\title{
Calcinosis of joints and periarticular tissues associated with vitamin $\mathrm{D}$ intoxication
}

\author{
R C BUTLER, P A DIEPPE, AND A C S KEAT \\ From the Departments of Rheumatology, Westminster Hospital and Bristol Royal Infirmary
}

SUMMARY We describe a patient with rheumatoid arthritis and widespread joint and periarticular calcinosis related to self-medication with vitamin $\mathrm{D}$, which was aggravated by oral $\stackrel{\oplus}{\oplus}$ phosphate therapy prescribed for her hypercalcaemia. Hydroxyapatite was shown in the synovial $ᄋ$ fluid from affected joints. The role played by tissue injury in the pathogenesis of soft tissue calcification is discussed.

Key words: hydroxyapatite, renal failure, crystals.

Soft tissue calcification is commonly seen in connective tissue diseases such as scleroderma or in patients with hypercalcaemia or hyperphosphataemia. Larger periarticular deposits of calcium are seen in tumoral calcinosis, a familial disease common in Negroes, which is often associated with hyperphosphataemia. ${ }^{1}$ Similar large deposits have been described in patients with chronic renal failure treated with haemodialysis, ${ }^{2}$ in the milk-alkali syndrome ${ }^{3}$ and in vitamin $\mathrm{D}$ intoxication. ${ }^{4}$

We report a patient with rheumatoid arthritis who developed chronic renal failure and extensive calcified swellings in periarticular soft tissues after selfmedication with cod liver oil. She had no episodes of acute arthritis and the carbonated apatite crystals identified in the swellings were relatively noninflammatory in laboratory tests, possibly as a result of surface coating.

\section{Case report}

A 48-year-old woman developed a symmetrical polyarthritis with typical rheumatoid erosions. She was treated with non-steroidal anti-inflammatory drugs, and between 1970 and 1975 with prednisolone, but her arthritis was progressive, and she

Accepted for publication 1 February 1985.

Correspondence to Dr R C Butler, Department of Rheumatology, Robert Jones and Agnes Hunt Orthopaedic Hospital, Oswestry, Shropshire SY10 7AG. required arthroplasties of both hips and knees. $\operatorname{In}$ September 1981 when aged 67 she complained of constipation, epigastric pain, and headaches. Inves- $\frac{\not}{D}$ tigation showed hypercalcaemia: $3.05 \mathrm{mmol} / \mathrm{l}$, albu- $\varrho$ min $30 \mathrm{~g} / \mathrm{l}$; renal failure: urea $23.3 \mathrm{mmol} / \mathrm{l}$ withö creatinine clearance $10 \mathrm{ml} / \mathrm{min}$ and phosphate $2 \cdot 13$ $\mathrm{mmol} / \mathrm{l}$; and nephrocalcinosis on plain abdominal film. Serum parathormone was less than $0 \cdot 1 \mu \mathrm{g} / 1$ 웅 (normal $0 \cdot 1-0.73 \mu \mathrm{g} / 1$ ), but the serum vitamin $\mathrm{D} \cong$ $\left(1 \alpha-\mathrm{OHD}_{3}\right)$ concentration was raised: $40 \mu \mathrm{g} / 1$ (nor-응 mal 11-23 $\mu \mathrm{g} / \mathrm{l})$. Her daughter said that for the 3 previous 18 months the patient had taken severalo tablespoons of cod liver oil, together with three mugs of milk daily.

She was advised to discontinue vitamin D supple-? ments and was treated with oral phosphate $4 \mathrm{~g}$ dailyo (equivalent to $1 \mathrm{~g}$ phosphorus) and a low calcium diet, and her plasma calcium returned to normalo (Fig. 1). Over the subsequent 14 months her plasman calcium remained within the normal range exceptr for two occasions when an attempt was made to ${ }_{\sigma}^{\omega}$ discontinue phosphate therapy, but the plasmaphosphate rose to $3 \mathrm{mmol} / \mathrm{l}$. She first noticed a? painful swelling of her right second toe in Aprilos 1981 , before phosphate treatment, and this enlarged ${ }_{T}$ subsequently; in September 1981 an $x$-ray of the left foot showed marked soft tissue calcification around尽 the left first metatarsophalangeal joint (Fig. 2), and

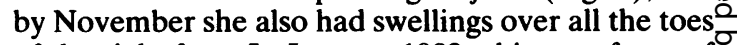
of the right foot. In January 1982 a biopsy of one of 


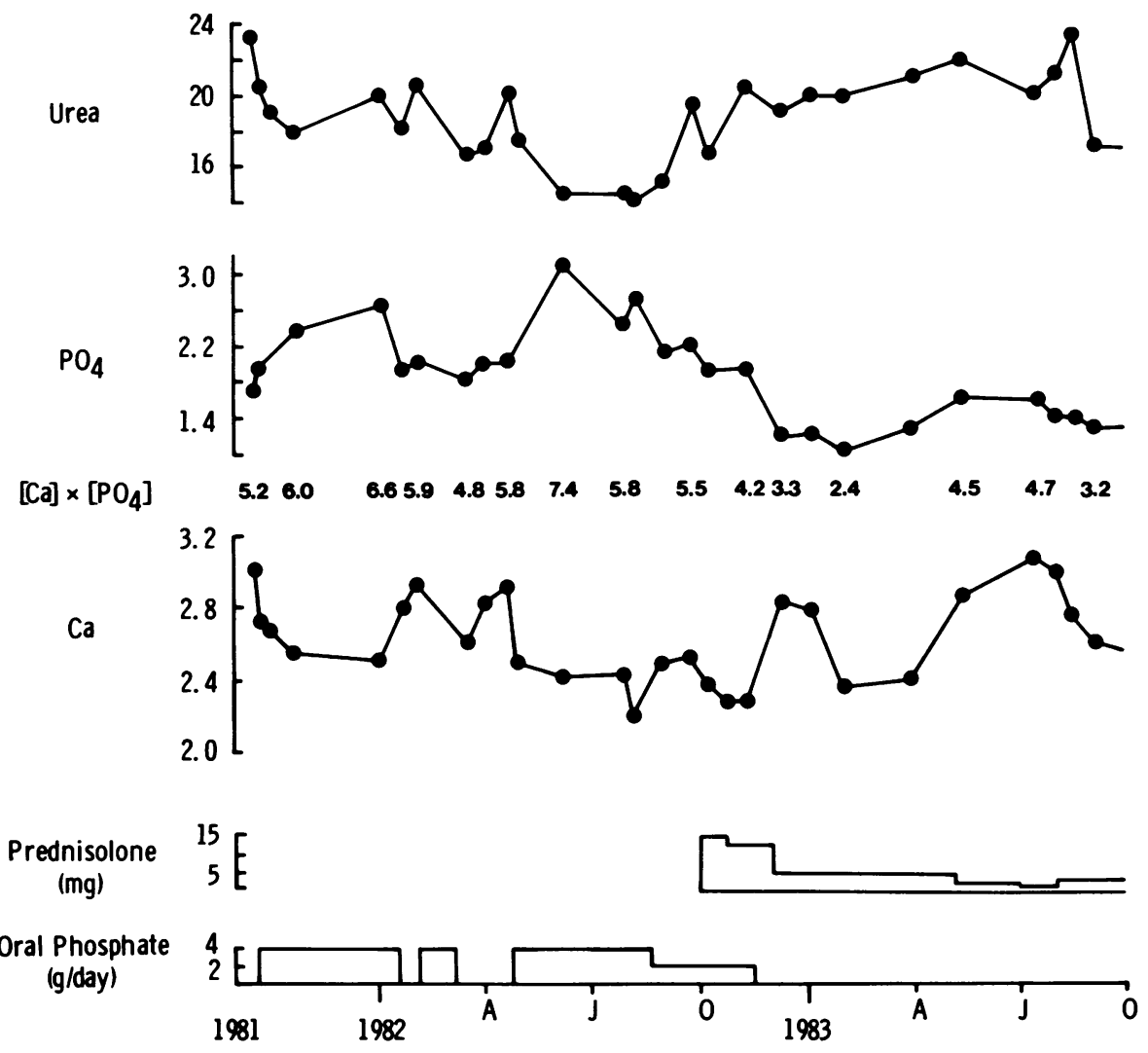

Fig. 1 Changes in plasma calcium and phosphate concentrations with different treatment regimens.

these areas revealed calcified necrotic material with surrounding giant cells. The wound was slow to heal and continued to discharge bloodstained creamy yellow fluid intermittently for five months. The toe remained painful, and she was readmitted for excision of the swelling; biopsy showed multiple deposits of calcium in the dermis surrounded by foreign body giant cells. Her postoperative recovery was complicated by laryngeal stridor due to cricoarytenoid arthritis.

By September 1982 she had developed olecranon bursitis, large swellings of the left wrist and right middle metacarpophalangeal joints, a swelling 10 $\mathrm{cm} \times 7 \mathrm{~cm}$ below the right inguinal ligament, and swelling of the toes and metatarsophalangeal joint of the left foot. $X$-rays showed that the swellings were associated with marked calcification (Fig. 3a). Plasma calcium was normal, but phosphate and urea were raised. Her mobility was greatly inhibited by generalised joint pains. Aspiration of the left wrist joint and of the swelling in the right groin showed bloodstained creamy fluid. The fluid was examined by light and electron microscopy. The predominant solid phase consisted of irregular, non-birefringent spherulites varying from $0 \cdot 1$ to $5 \mu \mathrm{m}$ in diameter. On infrared spectrophotometry the typical pattern of hydroxyapatite was obtained, with small absorption peaks indicative of carbonate substitution (Fig. 4). Strong protein bands were also present, but the type of protein associated with the mineral was not identified. Surface charge of the particles was assessed electrophoretically and found to be relatively low (patient's mineral particles $0.4 \mu \mathrm{m} / \mathrm{s} / \mathrm{V}$; standard hydroxyapatite crystals $0.78 \mu \mathrm{m} / \mathrm{s} / \mathrm{V}$ ). The inflammatory potential of the material was assessed by injections into the rat foot pad. The swelling produced was much less than that of an equal weight of pure, laboratory made hydroxyapatite (data not presented).

In view of her immobility she was treated with prednisolone $15 \mathrm{mg}$ daily with marked symptomatic improvement and a fall in plasma calcium, and she 


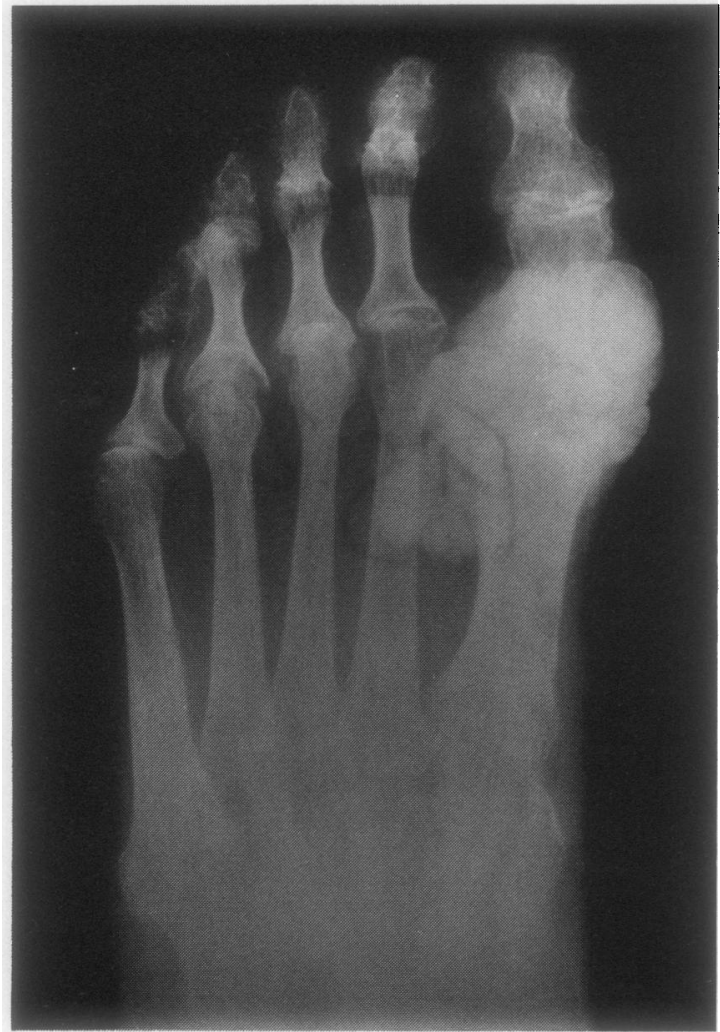

Fig. $2 X$-ray of left foot showing extensive periarticular soft tissue calcification.

was discharged from hospital. One month later she developed severe abdominal pain due to perforation of a duodenal ulcer, which was oversewn. After the operation oral phosphate was discontinued, her prednisolone was reduced to $5 \mathrm{mg}$ daily, and she was started on long-term cimetidine. The swellings decreased in size and by early January 1983 had disappeared, even though her plasma calcium was raised during this period. Between February and April it was maintained within the normal range on $4.5 \mathrm{mg}$ prednisolone daily, but when the dose of prednisolone was reduced her plasma calcium increased, only to fall again after a modest increase in dose from $1 \mathrm{mg}$ to $3 \mathrm{mg}$ daily (see Fig. 1). There has been no recurrence of the swellings, and $x$-rays no longer show calcinosis (Fig. 3b).

\section{Discussion}

Self-medication with cod liver oil is not uncommon in patients with rheumatoid arthritis but side effects appear to be rare. In the present case typica? gastrointestinal symptoms led to the diagnosis of: hypercalcaemia, when chronic renal failure and nephrocalcinosis were also discovered. Selfe medication was initially strongly denied, but once hyperparathyroidism had been excluded and n⿳亠丷厂 evidence of malignancy could be found, the patient' daughter was questioned and it emerged that hen mother had taken substantial quantities of vitamin $\mathrm{D}$ and milk for at least one year previously. The precise daily dose of vitamin $\mathrm{D}$ is uncertain but probably exceeded 5500 IU. Individuals differ im their susceptibility to vitamin D intoxication, but hypercalcaemia and raised serum vitamin $\mathrm{D}$ activity may persist for many months after discontinuation of vitamin D supplements. ${ }^{56} \mathrm{~A}$ low calcium diet and oral phosphate maintained her plasma calciuns within the normal range for the next 12 months, but over this period she developed a number of large periarticular swellings, while several such lesions present at the beginning of this period increased is size. These resembled tumoral calcinosis on $x$-ray $\vec{\varphi}$ and biopsy showed mononuclear and giant cets infiltration around areas of calcification, features similar to those described in that condition. ${ }^{7}$

The calcium $\times$ phosphate product, of which hyperphosphataemia is the major determinant, has a critical role in the genesis of soft tissue calcification in patients with renal failure: when it exceeds 5.84 (units in mmol/l) metastatic calcification is likelyo with lower values it is not. ${ }^{8}$ In our case control of plasma calcium concentration was achieved at the expense of an increase in plasma phosphate and of the calcium $\times$ phosphate product beyond thisू critical figure, and during this period soft tissue swellings increased rapidly in size. With hindsigh the risk of precipitation might have been anticipate $\$$ in view of the striking rise in plasma phosphate aftee initiation of phosphate therapy. There was dramatio clinical and radiographic improvement on subse quent discontinuation of phosphate and reduction og. the calcium $\times$ phosphate product below 5.0. Dietar restriction of phosphate, sometimes combined witkP aluminium hydroxide to reduce absorption of phos ${ }^{N}$ phate, has proved effective in the management of idiopathic tumoral calcinosis ${ }^{1}$ and that associated with haemodialysis. ${ }^{2}$

Soft tissue calcification has been classified as metastatic, when it is associated with abnormalities? of calcium or phosphate metabolism, or dystrophic $\square$ when it is secondary to local tissue damage; periaro

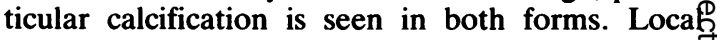
factors are important even in metastatic calcifica $\overrightarrow{\mathbb{Q}}$ tion: some patients studied by Katz et al. ${ }^{8}$ had no soft tissue calcification despite very high calcium $x_{0}$ 


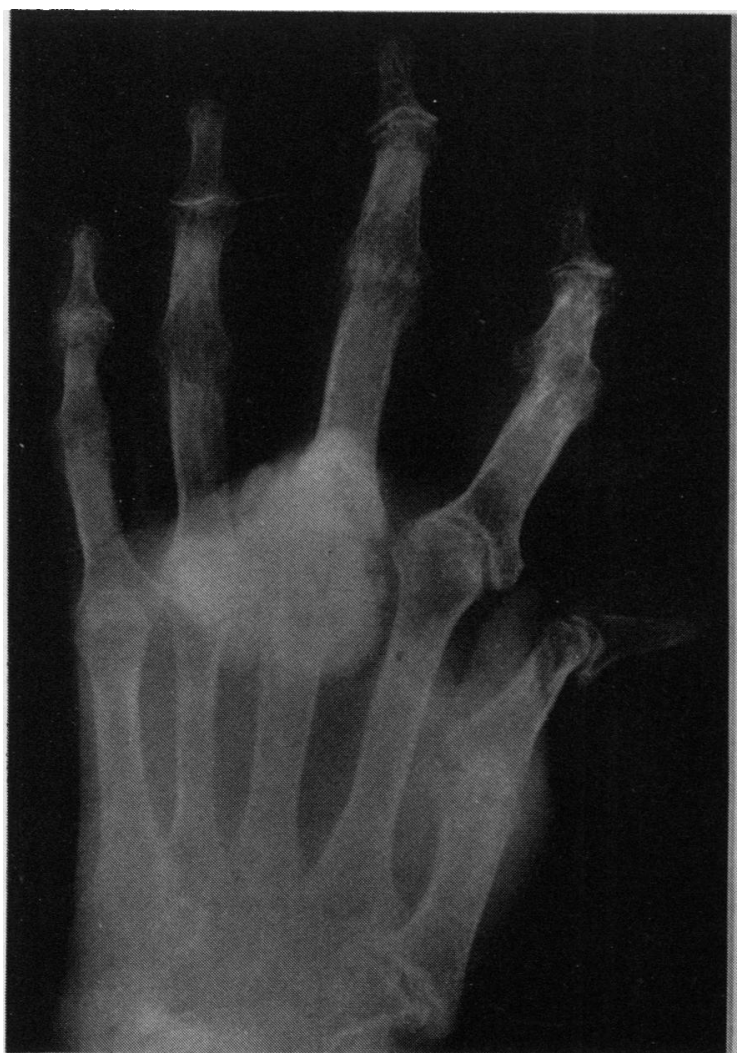

(a)

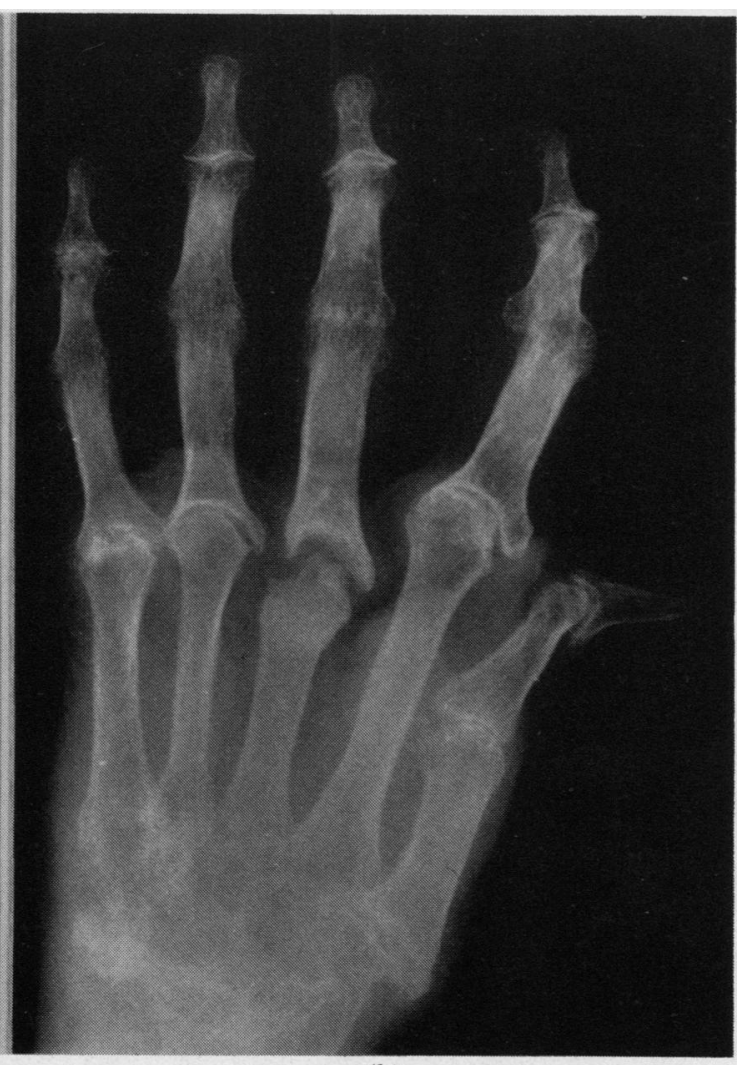

(b)

Fig. 3 (a) Extensive periarticular soft tissue calcification in left hand 11 months after initiation of phosphate therapy, which is no longer seen in (b) the $x$-ray taken 22 months after phosphate had been discontinued and oral prednisolone started.

phosphate products, and in the present case striking accumulations of calcified material were confined to previously damaged joints and overlying skin. This distribution resembles that reported by $\mathrm{Holman}^{4}$ in eight patients with hypervitaminosis $D$ who also had rheumatoid arthritis or gout: no such deposits were seen in a further 48 patients with hypervitaminosis $D$ who did not have chronic arthritis. These eight patients resembled the present case in the degree of hypercalcaemia, of hyperphosphataemia, and of renal failure; four had taken vitamin $D$ for a similar period of time, the remainder for between three and 14 years. As Holman pointed out, although damaged joints appear to provide a local stimulus to periarticular calcification, joints which appear to be involved to a similar extent might have extensive surrounding calcification or none at all. The nature of the local stimulus remains uncertain, though damaged avascular connective tissue is susceptible to calcification, ${ }^{910}$ perhaps due to loss of normal connective tissue inhibitors of crystal formation.

The material identified from the patient was hydroxyapatite in the form of spherulites as has previously been observed in periarticular 'dystrophic' deposits, with some carbonate substitution. ${ }^{11}$ Other mineral phases may have been present but only in very small amounts. As in the case of urate and pyrophosphate crystals apatites are sometimes seen in association with episodes of acute synovitis and have phlogistic potential. ${ }^{12}$ However, the crystals are also found in asymptomatic joints without apparently causing inflammation. The lack of a marked inflammatory response to the particles in this case is unlikely to have been due to dose or size, since a vast amount of material with varying particle size was present. The main determinant of crystal induced inflammation is probably the crystal surface $;{ }^{13}$ these particles had a low surface charge 


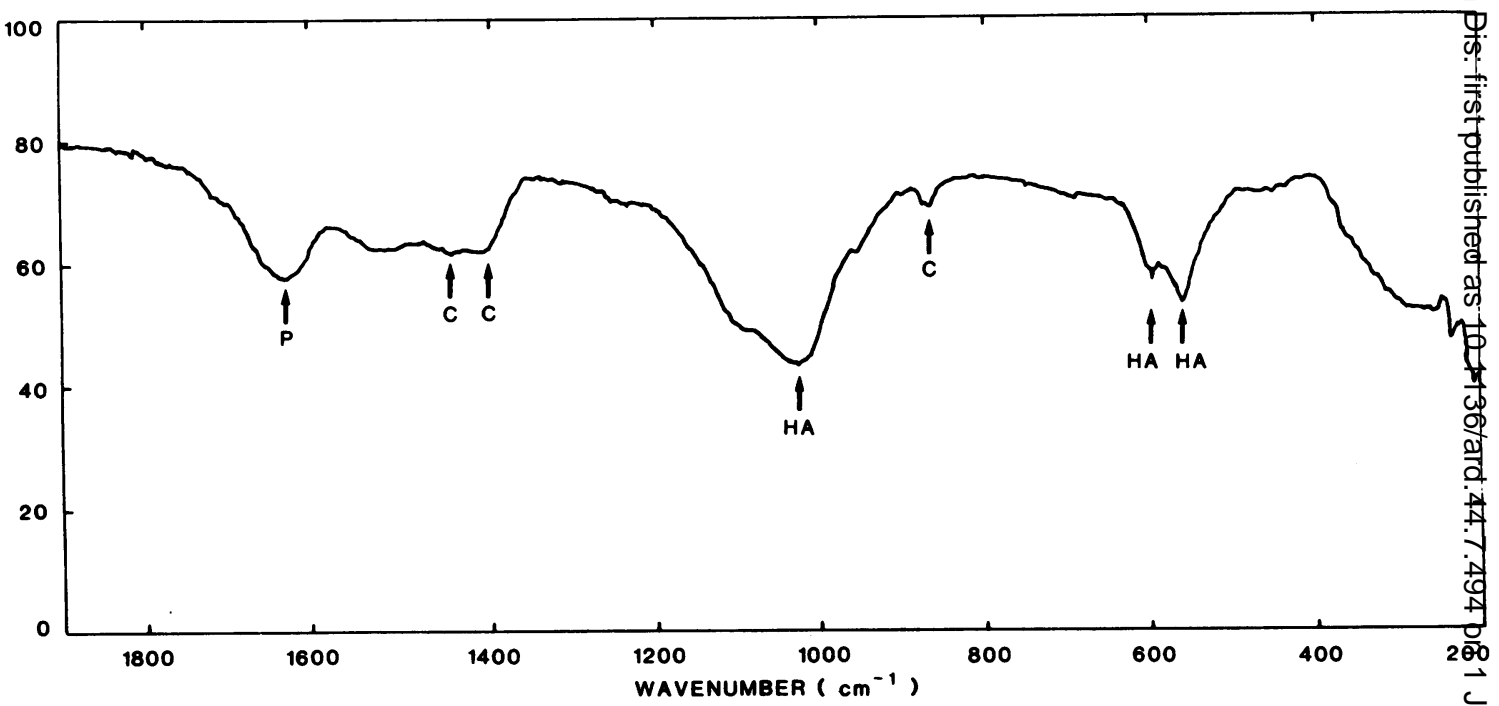

Fig. 4 Infrared spectroscopic tracing of washed calcific material from the patient's knee joint. Note the presence of protein $(P)$, large amounts of hydroxyapatite $(H A)$, and carbonate $(C)$. The positioning of the $H A$ and $C$ peaks is typical of partially carbonated hydroxyapatite. The presence of protein within the washed material suggests that there may have been some persisting attachment to the crystal surfaces.

and were associated with an unidentified mixture of proteins that may have affected their ability to activate an acute inflammatory response. It has recently been suggested that lipoproteins may have an inhibitory effect on crystal induced inflammation, ${ }^{14}$ and it is possible that the presence of this or other substances in the rheumatoid joints prevented the development of acute synovitis.

It was recognised 30 years ago that patients with rheumatoid arthritis are particularly susceptible to soft tissue calcification during treatment with high doses of vitamin D. ${ }^{4}$ Vitamin $\mathrm{D}$ intoxication remains a hazard, ${ }^{15}$ and complications of self-medication with this vitamin may present a growing problem if patients turn to 'alternative' cures in increasing numbers.

\section{References}

1 Mozaffarian G, Lafferty F W, Pearson O H. Treatment of tumoral calcinosis with phosphorus deprivation. Ann Intern Med 1972; 77: 741-5.

2 Massrey S G, Bluestone R, Klinenberg J R, Coburn J W. Abnormalities of the musculoskeletal system in haemodialysis patients. Semin Arthritis Rheum 1975; 4: 321-49.

3 Wermer P, Kuschner M, Riley E A. Reversible metastatic calcification associated with excessive milk and alkali intake. Am J Med 1953; 14: 108-15.
4 Holman C B. Roentgenologic manifestations of vitamin Dh intoxication. Radiology 1952; 59: 805-16.

5 Danowski T S, Winklet A W, Peters J P. Tissue calcification and renal failure produced by massive dose vitamin $\mathrm{D}$ therapy of arthritis. Ann Intern Med 1945; 23: 22-9.

6 Lumb G A, Mawer E B, Stanbury S W. The apparent vitamin D resistance of chronic renal failure. A study of the physiolog? of vitamin D in man. Am J Med 1971; 50: 421-41.

7 Slavin G, Klenerman L, Darby A, Bansal S. Tumoral calcinosis్ in England. $\mathrm{Br}$ Med $J$ 1973; i: 147-50.

8 Katz A I, Hampers C L, Merrill J P. Secondary hyperpara thyroidism and renal osteodystrophy in chronic renal failure? Medicine (Baltimore) 1969; 48: 333-74.

9 Uhthoff H K. Sarkar K, Maynard J A. Calcifying tendinitis: new concept of its pathogenesis. Clin Orthop 1976; 188: 164-8

10 Dieppe P. Crystal deposition disease and the soft tissues. Clin Rheum Dis 1979; 5: 807-22.

11 McCarty D J, Gatter R A. Recurrent inflammation associate 7 with focal apatite crystal deposition. Arthritis Rheum 1966; 9. 804-19.

12 Schumacher H R, Miller J L, Ludivico C, Jessar R A. Erosivฮ arthritis associated with apatite crystal deposition. Arthritis Rheum 1981; 24: 31-7.

13 Mandel N S, Mandel G S. Monosodium urate monohydrateE the gout culprit. J Am Chem Soc 1976; 98: 2319-23.

14 Terkeltaub R, Curtiss L K, Tenner A J, Ginsberg M H Lipoproteins containing apoprotein $\mathrm{B}$ are a major regulator neutrophil responses to monosodium urate crystals. J Clif Invest 1984; 73: 1719-30.

15 Davis $M$, Adams $P H$. The continuing risk of vitamin- $D$ intoxication. Lancet 1978; ii: 621-3. 